\title{
CLUSTER - ARRANJO PRODUTIVO LOCAL - COMO INSTRUMENTO PARA O DESENVOLVIMENTO SUSTENTÁVEL
}

\author{
Márcio Luís de Oliveira ${ }^{1}$ \\ Vinicius Diniz e Almeida Ramos ${ }^{2}$
}

\section{Resumo}

Este artigo tem como objetivo analisar a adequação do modelo de cluster (Arranjo Produtivo Local - APL) como instrumento hábil na promoção do desenvolvimento nacional sustentável e regionalizado. Por meio de pesquisa bibliográfica descritiva, buscou-se, inicialmente, abordar a amplitude do conceito de sustentabilidade que, além da vertente ambiental, fundamenta-se também no desenvolvimento econômico e no bem-estar social. Nesse ponto, salientou-se que a Constituição brasileira atribui à Federação a função de incentivar e planejar a atividade econômica, cabendo-lhe, portanto, adotar políticas que se alinhem ao princípio do desenvolvimento sustentável e regionalizado. Para tanto, procurou-se demonstrar as características principais dos clusters e o papel da governança no seu aprimoramento, utilizando-se de APLs implementados no Estado de Minas Gerais para ilustrar casos bem-sucedidos de aglomerações industriais dessa espécie. Foram ainda destacadas experiências internacionais com clusters, aludindo-se aos modelos italiano, francês, português e espanhol. Ao final, concluiu-se que os Arranjos Produtivos Locais, se bem organizados e planejados, são um modelo de atividade empresarial que se coaduna com os preceitos do desenvolvimento sustentável e regionalizado, merecendo do Estado a adoção de políticas públicas de incentivo e de planejamento.

Palavras-chave: Cluster, Arranjo Produtivo Local; Desenvolvimento sustentável; Incentivo; Planejamento.

\footnotetext{
${ }^{1}$ Doutor em Direito (UFMG). Professor Adjunto de Graduação e do Mestrado em Direito Ambiental e Desenvolvimento Sustentável da Escola Superior Dom Helder Câmara. Professor Adjunto de Direito Constitucional do Departamento de Direito Público da Faculdade de Direito da UFMG. E-mail: marcio.luis@uol.com.br

${ }^{2}$ Mestre em Direito pela Escola Superior Dom Helder Câmara (ESDHC).E-mail: vinicius@fiemg.com.br
} 


\section{INTRODUÇÃO}

Os clusters, também denominados Arranjos Produtivos Locais - APLs, caracterizados pela aglomeração de empreendimentos do mesmo segmento (ou de segmentos que compõem uma cadeia produtiva) e localizados na mesma região geográfica, vêm ganhando importância no Brasil desde o final do século XX e início do século XXI, quando se reconheceu, nesse tipo de organização empresarial, vantagens que envolvem principalmente aspectos econômicos e sociais.

No Brasil, a consecução do desenvolvimento nacional regionalizado e sustentável é, nos termos da Constituição, um objetivo a ser alcançado, em sinergia, pelos entes da Federação, iniciativa privada e sociedade. Destaca-se, entretanto, que a sustentabilidade não se vincula exclusivamente ao fator ambiental, mas engloba, no mesmo grau de relevância, também o crescimento econômico e a equidade social, a qual tem, como um de seus pilares, a geração de trabalho e renda.

Nesse contexto, o artigo suscita o seguinte problema: o cluster é um modelo de atividade empresarial capaz de se compatibilizar com o projeto de desenvolvimento nacional regionalizado e sustentável, de modo a merecer do Estado o incentivo e o planejamento a que fazem referência o artigo 174 da Constituição?

De modo a responder ao tema-problema, adota-se a hipótese de que o APL, pela maneira como pode ser organizado e por suas características, detém potencialidade para gerar benefícios diversos para as regiões onde são implementados; as vantagens vão desde a geração de emprego e renda, até a criação de infraestrutura logística e educacional alinhada às vocações regionais e à preservação da cultura e das tradições locais. Sob esta perspectiva, serão analisados o surgimento, o aperfeiçoamento e a tipologia do cluster, enfatizando-se suas características principais e os benefícios econômicos e sociais que podem proporcionar. Logo, a hipótese para a análise do cluster irá aferir se este modelo de empreendedorismo é capaz de responder positivamente à pergunta formulada.

O marco teórico a ser utilizado é o instituto do cluster como modelo político-econômico de empreendedorismo surgido na Itália e sua aplicabilidade ao paradigma do desenvolvimento socioeconômico sustentável.

O objetivo geral do trabalho é abordar a amplitude do conceito de desenvolvimento sustentável, que se consolida a partir da conjugação do crescimento econômico, da equidade social e da proteção do meio ambiente. Procurar-se-á demonstrar que, não obstante o forte apelo ambiental, o crescimento econômico é igualmente imprescindível para a melhoria das condições sociais e regionais. Logo, o artigo terá como objetivos específicos: a) avaliar se o empreendedorismo por meio de cluster pode contribuir para o desenvolvimento nacional sustentável e regionalizado, em conformidade com as normas da Constituição; b) e, se assim for, se o Estado deve 
implementar políticas públicas que incentivem a criação e o aprimoramento do cluster como modelo de empreendedorismo.

Como metodologia, o trabalho foca-se no levantamento e na análise da bibliografia sobre o cluster (pesquisa bibliográfica descritiva), bem como no estudo de casos em que o cluster vem sendo utilizado como modelo de empreendedorismo em alguns países e regiões do Brasil. Assim, a metodologia do direito comparado será relevante para atestar a qualidade do modelo de cluster.

Inicia-se a pesquisa com o debate acerca da amplitude do conceito de desenvolvimento sustentável, que se consolida a partir da conjugação do crescimento econômico, da equidade social e da proteção do meio ambiente. Procurar-se-á demonstrar que, não obstante o forte apelo ambiental, o crescimento econômico é igualmente imprescindível para a melhoria das condições sociais.

Em seguida, investigar-se-ão as questões que envolvem o surgimento e aperfeiçoamento dos clusters, enfatizando-se suas características principais e os benefícios econômicos e sociais que proporcionam. Nesse ponto, ilustrar-se-á o funcionamento dos Arranjos Produtivos Locais com dois exemplos do Estado de Minas Gerais: o APL calçadista de Nova Serrana e o APL de eletroeletrônica de Santa Rita do Sapucaí.

Como complemento, buscar-se-á, ainda que de forma sucinta, abordar experiências internacionais com o sistema de clusters, com o foco das atenções voltado para os modelos francês, português e espanhol.

Finalmente, procurar-se-á esclarecer se os APLs, em face de suas características, são um modelo de atuação empresarial que se coaduna com o princípio do desenvolvimento sustentável, merecendo, se assim for, políticas estatais que incentivem sua criação e aprimoramento.

\section{A AMPLITUDE DO DESENVOLVIMENTO SUSTENTÁVEL}

A ideia do desenvolvimento sustentável encontra suas origens na Conferência de Estocolmo de 1972. Entretanto, a expressão somente foi forjada no Relatório Brundtland, de 1987, elaborado pela Comissão Mundial sobre Meio Ambiente e Desenvolvimento, significando o atendimento das necessidades das atuais gerações sem o comprometimento da capacidade das gerações vindouras também suprirem as suas necessidades.

Em razão do apelo ambiental emergente no século XX, o conceito acabou, por equívoco, sendo vinculado e se conformando quase que exclusivamente à proteção e preservação do meio ambiente, a ponto de se afirmar que

[...] a sustentabilidade passou a ser um componente essencial de um desenvolvimento que se preocupa não só com a qualidade de vida das pessoas, mas também com a qualidade do meio ambiente, mantendo-o preservado para o futuro. Isso significa que qualquer ação da sociedade deve atender às necessidades humanas sem comprometer os ciclos naturais, isto é, 
proceder à retirada dos recursos necessários de forma que a natureza possa se recuperar, e, quando for impossível essa recuperação, pensar em alternativas que evitem seu uso (BITTENCOURT, 2014, p. 1-2).

Muito embora o desenvolvimento sustentável tenha como uma de suas vertentes o meio ambiente, não se pode esquecer que seu cerne vai além da proteção ambiental, devendo ser considerados em seu bojo outros aspectos de igual relevância. É nesse sentido que Thomé (2014, p. 58) afirma que o desenvolvimento somente poderá ser considerado sustentável se o crescimento econômico, a preservação ambiental e a equidade social forem efetiva e simultaneamente respeitados.

Para Araújo e Arruda (2010, p. 291), “O desenvolvimento sustentável visa equacionar esse espectro de utilização dos recursos por uma via moderada de utilização com responsabilidade econômica, social e de distribuição de riquezas.”

De igual modo, leciona Nardes et al(2014, p. 35) que

[...] não há como alcançar melhorias consistentes na qualidade de vida da população sem uma fonte de riqueza que as financiem. É o crescimento econômico contínuo que permite o conforto das pessoas (traduzido pela disponibilidade de energia elétrica, boas estradas, água encanada, rede de esgotos, celulares, internet). Também não há como criar empregos sem uma economia robusta e ninguém, racionalmente, se considerará desenvolvido estando apenas na plateia.

Desse modo, o desenvolvimento sustentável pressupõe a harmonização dos aspectos econômicos, sociais e ambientais, não se podendo admitir que nenhum deles se sobreponha aos demais. Nem a preservação ambiental deve constituir-se em óbice ao desenvolvimento, nem este deve ser perseguido à custa da exclusão social e do consumo desarrazoado dos recursos naturais.

Há, contudo, quem entenda que a expressão "desenvolvimento sustentável” denota certa contradição. Machado (2014, p. 70), por exemplo, afirma que "O antagonismo dos termos - desenvolvimento e sustentabilidade - aparece muitas vezes, e não pode ser escondido e nem objeto de silêncio por parte dos especialistas que atuem no exame de programas, planos e projetos de empreendimentos”.

Não nos parece razoável a afirmação do autor. Primeiro, porque o termo "sustentável", etimologicamente, significa o que pode ser sustentado, mantido, passível de sustentação, defensável, suportável (HOUAISS e VILLAR, 2009, p. 1797). Segundo, porque “desenvolvimento”, nos termos da Resolução 41/128 da Organização das Nações Unidas - ONU, datada de 1986, conceitua-se como o

[...] processo global, econômico, social, cultural e político que visa a melhorar continuamente o bem-estar do conjunto da população e de todos os indivíduos, embasado em suas participações ativa, livre e significativa no desenvolvimento e na partilha equitativa das vantagens que daí decorrem.

Assim, ao invés de antagônicos, percebe-se que a expressão "desenvolvimento sustentável" se perfaz de dois termos perfeitamente conciliáveis, eis que o conceito de desenvolvimento preconizado pela ONU, por si só, 
já induz à ideia de sustentabilidade. Em outros termos, pode-se afirmar que não há desenvolvimento se não houver mecanismos que deem sustentação ao processo de melhoria contínua.

Há que se distinguir, entretanto, as diferenças conceituais entre crescimento e desenvolvimento. O primeiro, "constitui um processo através do qual a renda per capita de uma dada sociedade se eleva persistentemente. Acompanhando este crescimento, ocorre uma série de transformações estruturais de ordem quantitativa e qualitativa". O segundo, por sua vez, "pressupõe que, paralelamente ao primeiro processo, a maior parte da população dessa sociedade seja a principal beneficiária desse conjunto de transformações estruturais" (CACCIAMALI, 2001, p. 437).

Observa-se que o conceito de desenvolvimento é mais abrangente que o de crescimento, incluindo, além do fator essencialmente econômico, também questões relacionadas ao bem estar e à melhoria das condições de vida da sociedade. Por sua vez, sedimenta-se o entendimento de que a sustentabilidade - ou seja, a qualidade de ser sustentável -, conforme a definição já apresentada neste trabalho, não se vincula exclusivamente à questão ambiental.

Dessa forma, deve-se entender que o desenvolvimento sustentável tem como premissa o estabelecimento de políticas públicas (contemplando o crescimento econômico, a geração de trabalho e renda, e a proteção e preservação dos recursos naturais) que possam ser mantidas, que sejam passíveis de sustentação e que, como consequência, propiciem melhorias contínuas no bem estar da sociedade.

\section{O desenvolvimento sustentável na Constituição brasileira}

O estudo da Constituição da República Federativa do Brasil não deixa dúvidas de que o país incorporou em seu sistema jurídico o princípio do desenvolvimento sustentável. Já no preâmbulo, anuncia que a instituição do Estado Democrático de Direito se destina a "assegurar o exercício dos direitos sociais e individuais, a liberdade, a segurança, o bem-estar, o desenvolvimento" etc.

No artigo $1^{\circ}$, inciso IV, a Constituição destaca a livre iniciativa como um dos fundamentos da República e, no artigo 30, delineia objetivos que, em seu conjunto, traduzem o conceito de desenvolvimento sustentável:

Art. $3^{\circ}$. Constituem objetivos fundamentais da República Federativa do Brasil:

I - constituir uma sociedade livre, justa e solidária;

II - garantir o desenvolvimento nacional;

III - erradicar a pobreza e a marginalização e reduzir as desigualdades sociais e regionais;

IV - promover o bem de todos, sem preconceitos de origem, raça, sexo, cor, idade e quaisquer outras formas de discriminação.

Nos artigos 170 a 181, o texto constitucional trata dos princípios gerais da atividade econômica, merecendo destaque o disposto no artigo 170, do qual extrai-se o seguinte excerto: 
Art. 170. A ordem econômica, fundada na valorização do trabalho humano e na livre iniciativa, tem por fim assegurar a todos existência digna, conforme os ditames da justiça social, observados os seguintes princípios:

$[\ldots]$

IV - livre concorrência;

$[\ldots]$

VI - defesa do meio ambiente, inclusive mediante tratamento diferenciado conforme o impacto ambiental dos produtos e serviços e de seus processos de elaboração e prestação;

VII - redução das desigualdades regionais e sociais; [...]

É interessante notar que o inciso VII, do artigo 170, reforça o que já estabelecia o artigo 3º, inciso III, da Constituição, que fixou como um dos fundamentos da República a redução das desigualdades sociais e regionais, o que denota "a tentativa do legislador constituinte originário de manter o equilíbrio do pacto federativo mediante a exortação ao harmônico relacionamento entre os Estados da Federação brasileira, fato que somente acontecerá se não houver graves disparidades entre as suas economias" (SILVA NETO, 2010, p. 285).

O artigo 174, por fim, atribui ao Estado o papel de agente normativo e regulador da atividade econômica, cabendo-lhe as funções de fiscalização, incentivo e planejamento, tendo este último caráter apenas indicativo para o setor privado. Leciona Silva (2014, p. 820) que o incentivo a que se refere o dispositivo traduz a ideia do Estado como promotor da economia que, através do fomento, busca estimular, apoiar, favorecer e auxiliar a iniciativa privada nas atividades que venham satisfazer as necessidades ou conveniências de caráter geral, sem o emprego de meios coativos.

Tal atribuição estatal, entretanto, deve ser realizada a partir de um planejamento, que nada mais é que

[...] um processo técnico instrumental para transformar a realidade existente no sentido de objetivos previamente estabelecidos. O planejamento econômico consiste, assim, num processo de intervenção estatal no domínio econômico com o fim de organizar atividades econômicas para obter resultados previamente colimados (SILVA, 2014, p. 821).

Portanto, a interpretação conjunta dos dispositivos constitucionais acima indicados leva à compreensão de que é função do Estado, por meio do incentivo e do planejamento (artigo 174), promover políticas, fomentar a economia e estimular a iniciativa privada no sentido de se alcançar o crescimento econômico, a redução das desigualdades regionais e sociais (artigos 3º, inciso III e 170, inciso VII) e a proteção ambiental: pilares que dão fundamento ao desenvolvimento sustentável preconizado na Constituição.

\section{ORIGEM E CARACTERIZAÇÃO DOS CLUSTERS}

Inicialmente, é relevante apontar que modelos de aglomeração empresariais são bastante antigos, não se tendo sequer registro de quando surgiram. Entretanto, sua sistematização, organização e desenvolvimento se deu a partir da experiência italiana, já na segunda metade do século XX. 
Melo (2006, p. 31) lembra que, na Itália, a partir de 1975, pequenas empresas localizadas em regiões específicas - diferentemente do que ocorria com as grandes organizações - começaram a demonstrar um dinamismo pouco comum, elevando significativamente sua participação no mercado e gerando lucro e empregos. Esse desempenho econômico diferenciado nas indústrias concentradas no centro e nordeste da Itália

[...] não era explicado pelas teorias económicas tradicionais, uma vez que apresentavam características pouco comuns: eram constituídas maioritariamente por pequenas e médias empresas, eram inovadoras e tinham êxito internacional. As mais notáveis, no que dizia respeito à imagem externa e valor acrescentado, eram a indústria têxtil em Carpi e no Prato, a indústria cerâmica (azulejos) no Sassuolo, a indústria de mobiliário em Brianza e Cascina e a indústria de calçado em Vigevano e Puglia. A unidade de análise passa a ser não a empresa individual, mas um cluster de empresas interligadas e localizadas numa área geográfica pequena (MELO, 2006, p. 31).

Importante mencionar que todos os estudos a respeito de clusters partiram dessa experiência vivenciada na Itália, cujo modelo caracterizava-se pela prevalência das pequenas empresas, estabelecimento de um complexo relacionamento entre elas e, por fim, relação intensa dessas empresas com a comunidade local (KELLER, 2008, p. $34)$.

A experiência italiana é, portanto, um marco para o estudo e, por consequência, para a disseminação do modelo de cluster por todo o mundo. É possível extrair-se, do tipo ideal concebido na Itália, pelo menos quatro fatores essenciais próprios dos arranjos industriais:

[...] primeiro, um aglomerado de empresas (cluster), principalmente de tamanhos pequeno e médio, espacialmente concentradas e setorialmente especializadas; segundo, um conjunto de encadeamentos para frente e para trás, tendo por base a troca (ou intercâmbio, mercadológico ou não) de bens, de informações e de pessoas; terceiro, um fundo cultural e social comum unindo os agentes e criando um código de comportamento (explícito ou implícito); quarto, uma rede de instituições locais públicas e privadas apoiando os agentes econômicos que atuam dentro do cluster (KELLER, 2008, p. 35).

Os clusters, também denominados Arranjos Produtivos Locais - APLs ou distritos industriais, traduzem-se na organização planejada de conglomerados empresariais do mesmo segmento ou integrantes da mesma cadeia produtiva, cujas características principais são a concentração geográfica, a especialização setorial, a integração dos atores envolvidos e a cooperação entre as sociedades empresárias (AQUINO e BRESCIANI, 2005, p. 166). Pode-se também caracteriza-los como "aglomerações territoriais de agentes econômicos, políticos e sociais, que têm foco em um conjunto específico de atividades econômicas e que apresentam vínculos entre si” (ERBER, 2008, p. 12).

O estudo acerca do modelo de clusternão ficou restrito

[...] aos distritos industriais italianos, mas estendeu-se para diversas outras experiências de aglomeração nos países avançados e depois para os países em desenvolvimento. Tornou-se consenso na literatura, durante a década de 1990, que essa situação industrial é particularmente relevante para o estágio de industrialização incipiente, além de ajudar firmas pequenas e médias nos países em desenvolvimento, colaborando para que estas empresas 
cresçam mesmo em situações de maior risco, como as que surgem com o advento da globalização (KELLER, 2008, p. 32).

Não obstante a natural concorrência entre as indústrias que compõem determinado cluster, são a cooperação e a sinergia os pontos que o destacam. A disseminação de novas tecnologias, os investimentos na formação e no aperfeiçoamento da mão de obra, o compartilhamento da infraestrutura e dos sistemas de logística, e a prospecção de mercados para os produtos são aspectos marcantes, que formam o elo entre as sociedades empresárias e demais agentes participantes dos Arranjos Produtivos Locais.

Os clusters podem surgir de forma espontânea, mas seu desenvolvimento depende da participação de diversos atores: indústrias, Poder Público e outras instituições (que prestam serviços de treinamento de mão de obra, assistência técnica e assistência mercadológica, e que atuam na articulação entre esses mesmos atores, podendo-se citar como exemplos os sindicatos representativos das indústrias). Cabe ainda mencionar que uma estrutura de governança é fator indispensável na competitividade e organização do APL, em especial porque

Num contexto estático, a eficiência coletiva do APL tem como foco o uso mais eficiente dos seus ativos e a governança principal se traduz em rotinas. No entanto, num contexto em evolução, a competitividade do APL depende dos investimentos feitos na transformação dos ativos e rotinas, decididos por meio da governança das estratégias.

As estratégias de investimento e distribuição de resultados desses investimentos dentro de um APL são fortemente afetadas pela distribuição de poder dentro do arranjo, pela hierarquização da governança (ERBER, 2008, p. 20-21).

Ressalta-se que o termo "governança” comporta diversos entendimentos. Apesar disso, a transparência, o direcionamento das ações, o controle de uso dos recursos e a capacidade de articulação e de coordenação dos stakeholders (denominação dada ao grupo de pessoas que têm interesse em determinado negócio) são pontos comuns. Sua principal finalidade é assegurar que a execução do planejamento atinja os objetivos e resultados colimados de maneira transparente e efetiva (NARDES et al, 2014, p. 181-182).

Como parte integrante da estrutura de governança, cabe ao Estado atuar no planejamento e no fomento dos clusters, cumprindo-lhe

[...] várias funções, dentre as quais destacam-se o provimento de infraestrutura adequada, o apoio à educação e treinamento de mão de obra, o incentivo às atividades dos centros de pesquisa e a interlocução com as entidades representativas das sociedades empresárias (IACONO e NAGANO, 2007, p. 40-41).

É através desse trabalho que o Poder Público cumpre seu papel de incentivador do desenvolvimento sustentável (obrigação que lhe é imposta pela própria Constituição), o qual não pode ficar restrito aos habituais e tradicionais mecanismos de comando e controle (como o licenciamento ambiental, por exemplo), devendo-se estender pela promoção de políticas de desenvolvimento que efetivamente se traduzam em crescimento econômico, equidade social (sendo um de seus principais ingredientes a geração de trabalho e renda) e preservação ambiental (com o adequado uso e ocupação do solo atinentes ao APL, o condicionamento ambiental 
de projetos empresariais etc.).

\section{Os clusters no Estado de Minas Gerais}

Em Minas Gerais, dois estudos merecem destaque no que tange ao mapeamento das principais aglomerações produtivas do Estado, sendo considerados os pontos de partida para sua política de clusters: o Cresce Minas, no ano 2000, contratado pela Federação das Indústrias do Estado de Minas Gerais - FIEMG junto à Consultoria McKinsey; e o Minas Gerais no Século XXI, no ano de 2003, financiado pelo Banco de Desenvolvimento de Minas Gerais - BDMG (BNDES, 2015, p.9).

Ademais, as ações do Grupo de Trabalho Permanente de Arranjos Produtivos Locais - GTP-APL, instituído em 2004 pelo Ministério do Desenvolvimento, Indústria e Comércio Exterior - MDIC, foram responsáveis pela identificação de dez APLs mineiros que mereceram, naquela oportunidade, prioridade de apoio, destacando-se, dentre eles, o APL de Calçados de Nova Serrana e o APL de Eletroeletrônica de Santa Rita do Sapucaí (BNDES, 2015, p. 24), os quais serão, a seguir, objeto de verificação mais aprofundada.

\subsubsection{Ocluster de Calçados de Nova Serrana}

Nova Serrana localiza-se no centro-oeste mineiro, distante 133 quilômetros de Belo Horizonte. De acordo com o Sindinova (2007, p. 4), o polo calçadista local surgiu de forma espontânea a partir de 1920. Contudo, foi com a emancipação do Município, em 1954, que a produção de calçados passou a se desenvolver de forma rápida. Além de Nova Serrana - líder do aglomerado empresarial e que conta com cerca de 800 empresas o cluster é composto, ainda, pelos Municípios de Perdigão, Araújos, São Gonçalo do Pará, Bom Despacho, Conceição do Pará, Divinópolis, Igaratinga, Leandro Ferreira, Onça do Pitangui, Pará de Minas e Pitangui, dando formação a um dos maiores polos calçadistas do Brasil.

Dados também revelados pelo Sindinova (2007, p. 4-5) apontam que o APL é responsável por 55\% (cinquenta e cinco por cento) da produção de tênis nacional. A indústria calçadista do Arranjo emprega cerca de 68\% (sessenta e oito por cento) da mão de obra ativa da região. O Índice de Desenvolvimento Humano - IDH do Município de Nova Serrana passou de 0,713 em 1991 para 0,801 em 2000, atingindo o nível de alto desenvolvimento humano, graças ao desenvolvimento econômico e social proporcionado pelo cluster.

O aprimoramento do Arranjo Produtivo Local de Nova Serrana forjou-se a partir da participação ativa de diversos órgãos e instituições, dentre os quais pode-se citar o Governo do Estado de Minas Gerais, o Ministério do Desenvolvimento, Indústria e Comércio Exterior - MDIC, a Federação das Indústrias do Estado de Minas Gerais - FIEMG, o Sindicato da Indústria do Calçado de Nova Serrana - SINDINOVA, a Associação Brasileira 
das Indústrias de Calçados - ABICALÇADOS, o Banco Nacional de Desenvolvimento Econômico e Social BNDES, o Serviço Brasileiro de Apoio às Micro e Pequenas Empresas - SEBRAE, dentre vários outros (SINDINOVA, 2007, p. 5-6). Esses atores permanecem atuando de forma conjunta, com vistas a promover o desenvolvimento do cluster.

Importante destacar que ao Governo do Estado, através do Instituto Industrial de Minas Gerais - INDI e da Secretaria de Estado de Desenvolvimento Econômico - SEDE, cabe realizar o planejamento, organização, direção, coordenação, execução, controle e avaliação das ações setoriais a cargo do Estado. Simultaneamente, o Sindicato da Indústria do Calçado de Nova Serrana

[...] empenha-se em promover o desenvolvimento do associativismo, propiciando condições de suporte técnico e financeiro à indústria local. Além disso, a entidade visa estimular a participação de seus associados em programas de gestão empresarial e coloca a (sic) disposição de seus associados um laboratório de testes, sistema de CAD-CAM e o centro de modelagem, visando à melhoria do padrão de qualidade da indústria local (SINDINOVA, 2007, p. 6).

No topo da hierarquia de governança está o Comitê Gestor do cluster de Nova Serrana, composto por representantes do Governo Federal, Governo Estadual, Governo Municipal, representantes das empresas, entidades de apoio, Universidades, Centros de Treinamento, entidades de classe e entidades de fomento, e liderado pelo Sindicato da Indústria do Calçado. Cabe ao Comitê, dentre outras atribuições, articular as forças políticas e empresariais, definir os programas de ação através do planejamento estratégico, levantar recursos financeiros para a execução dos programas de ação e gerenciar o processo de desenvolvimento do APL (SINDINOVA, 2007, p. 7).

Em trabalho de campo realizado junto às indústrias calçadistas do APL de Nova Serrana, foi possível identificar que os relacionamentos entre os agentes econômicos são sustentados pela obtenção de benefícios mútuos, sendo que esses benefícios são reconhecidos pelos atores envolvidos como fato relevante e imprescindível ao desenvolvimento das atividades empresariais (AZEVEDO etal,2015, p. 119).

Destaca Santos (2013, p. 58) que graças à formação e consolidação do cluster calçadista é possível alcançar-se alguns benefícios de forma coletiva, como, por exemplo, a capacitação de pessoal operacional e administrativo, a realização de diagnósticos setoriais relacionados à produtividade e à concorrência, a busca de recursos junto a órgãos de fomento por meio de projetos envolvendo as indústrias que compõem o APL, o avanço na área de pesquisa e desenvolvimento (P\&D), dentre vários outros.

No que se refere ao APL calçadista de Nova Serrana, é preciso reconhecer que

[...] os atores se relacionam por propósitos claros e previamente definidos, sempre com o intuito de acessar determinados recursos, sejam eles de natureza física ou informacional, $\mathrm{e}$ contemplam que na interação deve haver mutualidade, com ganhos auferidos por ambas as partes. Há, por parte dos próprios atores, o reconhecimento de que é necessário estabelecer 
relações de distintas naturezas e intensidade de vínculos, dentro e fora do arranjo produtivo (AZEVEDO etal,2015, p. 127).

O Arranjo Produtivo Local de Nova Serrana convive harmoniosamente com as individualidades de cada sociedade empresária (podendo cada uma delas ter seus próprios objetivos estratégicos). Assim, muitas empresas seguem caminhos diferentes: umas preferem desenvolver-se nos aspectos operacionais, outras nos aspectos administrativos. Essa questão é inerente à formação do APL, constituindo o binômio de cooperação e competição, em que as empresas são concorrentes em um mercado comum, ao mesmo tempo em que cooperam entre si em questões que acarretam ganhos mútuos (SANTOS, 2013, p. 61).

Muito embora possa se desenvolver de forma mais coesa e efetiva - especialmente no que se refere à melhoria da qualidade dos produtos e à abertura de mercado para a exportação -, o Arranjo Produtivo Local de Nova Serrana é um bom exemplo de cluster bem sucedido, em que são obtidos benefícios diversos ao conjunto das sociedades empresárias que o integram. A região é reconhecida nacionalmente como um polo calçadista de expressão. O índice de mão de obra empregada nas indústrias de calçado e o aumento do IDH do município comprovam que o APL é responsável pelo desenvolvimento socioeconômico regional.

\subsubsection{O cluster de Eletroeletrônica de Santa Rita do Sapucaí}

Localizada no sul do Estado de Minas Gerais, Santa Rita do Sapucaí fica a 384 quilômetros de Belo Horizonte, numa região conhecida como "Vale da Eletrônica". O cluster, liderado por Santa Rita, abrange ainda os Municípios de Itajubá e Pouso Alegre, contando com cerca de 120 empresas do segmento eletroeletrônico, das quais $80 \%$ (oitenta por cento) são micro ou pequenas empresas.

Ao relatar a origem e história do cluster, o Sindvel (2007, p. 4) destaca que a criação, em 1913, do Instituto Eletrônico e Mecânico de Itajubá (atual Universidade Federal de Itajubá - UNIFEI) provocou uma natural capacitação de trabalhadores na área de engenharia elétrica e mecânica, atraindo indústrias para aquela região. Esse cenário promissor viabilizou a criação, em 1959, da Escola Técnica de Eletrônica Francisco Moreira da Costa - ETE e, posteriormente, do Instituto Nacional de Telecomunicações - INATEL. Nos anos de 1970, a Faculdade de Administração e Informática - FAI passou a oferecer capacitação e especialização em eletroeletrônica, consolidando definitivamente a região como um importante polo tecnológico. Esse conjunto de instituições educacionais

[...]criam capacidade técnica em Eletrônica e Telecomunicações e motivam a geração de inúmeras empresas. Dados da Secretaria de Educação da cidade de Santa Rita do Sapucaí apontam cerca de 2 mil estudantes de nível superior na área de informática, telecomunicações, engenharia da computação e administração de empresas, além de cerca de 600 estudantes de nível técnico nas áreas de eletrônica e informática. Neste contexto, as empresas contam com recursos humanos de alta qualificação, com condições de se adaptar rapidamente às bruscas mudanças que caracterizam o mercado de produtos eletroeletrônicos (SINDVEL, 2007, p. 6). 
O APL de Eletroeletrônica destaca-se no cenário estadual e nacional por sua importância econômica. Apenas ilustrativamente, vale mencionar que o Produto Interno Bruto - PIB do Arranjo vem, desde 1999, apresentando crescimento superior à média brasileira (SINDVEL, 2007, p. 5).

De acordo com Pereira e Lorena (2014, p. 64), a relação entre as empresas integrantes do cluster contempla os diversos elos da cadeia produtiva da atividade local, proporcionando vantagens competitivas que, em seu conjunto, traduzem-se na denominada eficiência coletiva.

Duas características favorecem as iniciativas a ações coletivas no APL de Santa Rita do Sapucaí: sua composição, formada em grande parte por pequenas e médias empresas, e os produtos de alta tecnologia, que estimulam investimentos em pesquisa e desenvolvimento. Além disso, o cluster caracteriza-se pela "divisão do trabalho e da especialização entre produtores e fornecedores e matérias-primas e de máquinas", por uma classe trabalhadora qualificada e habilitada e, por fim, pela presença de "Associações para a realização de lobby e de tarefas específicas para o conjunto de seus integrantes" (MURAD et al, 2015, p. 5).

A competitividade da empresa está relacionada com a sua capacidade de promover inovação em todos os setores, e o cluster desempenha um papel importante na sua capacidade de inovação. A proximidade geográfica possibilita o aproveitamento dos benefícios trazidos pela inovação pelo fato de haver uma grande troca de informações entre as empresas, além da redução de custos de transação. Se uma empresa do cluster desenvolver ou obtiver uma inovação importante, ela logo se tornará pública em função das suas ações e contatos de rotina com os agentes do aglomerado (PEREIRA e LORENA, 2014, p. 65).

A governança do cluster de Santa Rita do Sapucaí é liderada pelo Sindicato das Indústrias de Aparelhos Elétricos, Eletrônicos e Similares do Vale da Eletrônica - SINDVEL, que compartilha sua gestão com a Federação das Indústrias do Estado de Minas Gerais - FIEMG e com o Serviço Brasileiro de Apoio às Micro e Pequenas Empresas - SEBRAE.

O APL do Vale da Eletrônica apresenta uma particularidade interessante. Enquanto, na maioria dos casos, um cluster é formado espontânea e desorganizadamente (sendo seu desenvolvimento, aí sim, dependente de planejamento e organização), na região de Santa Rita do Sapucaí foi o sistema educacional, voltado para a área eletrônica e mecânica (e, posteriormente, telecomunicações e informática), que provocou a atração de indústrias para aquela região, dando forma ao Arranjo.

O desenvolvimento econômico e social dos Municípios que integram o APL Eletroeletrônico é notório. Em 2010, o Índice de Desenvolvimento Humano - IDH do Município de Santa Rita do Sapucaí foi de 0,721, enquanto o do Município de Pouso Alegre foi de 0,774 e o do Município de Itajubá de 0,787. Por sua vez, o IDH do Estado de Minas Gerais, também em 2010, foi de 0,731, pouco acima do de Santa Rita e bastante inferior ao de Pouso Alegre e Itajubá. Inegável que tal desempenho deve-se à efetividade e pujança socioeconômica do cluster do Vale da Eletrônica. 


\section{EXPERIENCIAS INTERNACIONAIS COM CLUSTERS}

Além da Itália, onde se originou o cluster (conforme abordado no capítulo 3 do presente trabalho), há outras experiências internacionais de relevo.

Na França, as aglomerações de empresas (que recebem o nome de sistemas produtivos locais - SPL) tiveram início em 1998, constituindo-se principalmente por pequenos e médios empreendimentos industriais, que atuam de forma complementar e que "têm à sua disposição, bens e serviços, infra-estruturas (sic), um aparelho de formação, clubes de empreendedores, organizações especializadas que lhes fornecem esses bens locais coletivos" (BENKO, 2004, p. 12).

As políticas francesas de incentivo e de suporte aos SPL baseiam-se em projetos que, entretanto, são pouco diretivos no que se refere ao porte e ao grau de maturidade dos setores coletivos. De todo modo, o programa

[...] tenta coordenar instrumentos de apoio setoriais. Ele consegue animar ações coletivas entre empresas, principalmente, graças ao impulso de estruturas locais, tais como Câmaras de Comércio e de Indústrias ou das associações específicas. Trata-se de criar uma proximidade organizada nos locais, ou onde a proximidade geográfica já existe. Seus eixos principais consistem em fazer emergir os novos SPL, encorajar as ações comuns e da tomada de consciência das vantagens dessas últimas, dentro das aglomerações de empresas (BENKO, 2004, p. 17).

Tratando dos arranjos industriais em Portugal, Melo (2006, p. 32-33) salienta que, habitualmente, estes têm característica monosetorial, de modo que "a maioria das empresas contribui para uma mesma produção", seja fabricando produtos finais, seja especializando-se em produtos de fase, seja, ainda, prestando serviços de apoio (transporte, serviços financeiros, dentre outros). Dessa forma, cada uma das empresas é "especializada numa fase diferente do processo de fabrico de uma indústria dominante na região ou de uma série de indústrias complementares." Ressalta ainda a autora que, paralelamente, nota-se um sistema de instituições (educacionais, religiosas, familiares, políticas, mercadológicas etc.) cuja função é "disseminar o sistema de valores pelo distrito, de forma a mantê-lo e transmiti-lo de geração em geração."

No distrito de Águeda, a indústria mantém-se vinculada à fabricação de ferragens, mobiliário metálico, aparelhos elétricos e serviços industriais especializados. Esse cenário propiciou a definição de um setor industrial especializado, a formação e capacitação da mão de obra, a acumulação de cultura técnica industrial e a consolidação de um sistema de interdependências industriais.

Assim como no Brasil, o cluster de Águeda conta com atores essenciais, podendo-se fazer referência especial à Associação Industrial de Águeda (AIA), que disponibiliza serviços de consultoria de todo gênero, à Associação Nacional de Indústrias de Duas Rodas, Ferragens, Mobiliário e Afins (ABIMOTA), que presta apoio 
jurídico e econômico-financeiro aos seus associados, e à Associação Nacional de Indústrias de Ferragens (APIFER), cujo principal objetivo é organizar a participação de seus associados em feiras nacionais e internacionais, promover certificações de qualidade e estabelecer protocolos de cooperação (Melo, 2006, p. 49).

Em relação à experiência espanhola, López (1997, p. 103) destaca que os estudos realizados demonstram que raras vezes os arranjos produtivos alcançam a complexidade e grau de maturidade do modelo teórico (caracterizado pela concentração geográfica, especialização setorial, integração dos atores envolvidos e a cooperação entre as sociedades empresárias, contando com a participação ativa dos agentes econômicos, políticos e sociais), sendo o ponto mais frágil a escassa capacidade de inovação. Por esta razão, em regra, os segmentos integrantes dos aglomerados industriais dedicam-se à produção de bens de consumo de baixa complexidade tecnológica. Somente sete arranjos na Espanha especializaram-se em indústrias de alta tecnologia: Sabadell em software; Alto Deva, Bajo Deva, Manresa e Fuenlabrada em maquinaria; Vigo em componentes navais e Dos Hermanas em componentes aeronáuticos.

Quanto à distribuição espacial dos arranjos industriais no território espanhol, nota-se que

[...] la mayor concentración se da en las regiones mediterráneas: los 6 de Cataluña y los 11 de Valencia constituyen la tercera parte del total. Siendo éste el eje de desarrollo más dinámico de España, parece lógico pensar que los sistemas productivos locales han jugado un papel importante en su configuración y dinamismo, más aún si se tieneen cuenta el caráter urbano de la mayor parte de ellos (LÓPEZ, 1997, p. 103).

Não obstante contar a Espanha com uma política empresarial de clusters, o sistema apresenta fragilidades relevantes, especialmente quando se constata a falta de vocação para a inovação tecnológica e sua concentração nas regiões mediterrâneas: ao invés de servirem como instrumentos de interiorização do desenvolvimento, aglutinam-se em torno das grandes cidades espanholas.

Pode-se perceber a presença do sistema de clusters em vários outros países. Entretanto, para sua investigação, seria necessário maior aprofundamento. Não sendo o estudo comparado o objetivo primordial do presente trabalho, supõe-se que os exemplos acima mencionados são, por ora, suficientes para permitir uma reflexão acerca do assunto.

\section{CONCLUSÃO}

Os primeiros sinais de concertos empresariais no Brasil, ainda que não organizados, datam do início do século XX, como no caso da aglomeração calçadista no Município de Nova Serrana, em Minas Gerais, que teve origem espontânea no ano de 1920. Entretanto, o sistema brasileiro de cluster é recente, datando do final do último século. Foi somente nessa época que o tema passou a ganhar importância e integrar o planejamento da 
atividade econômica, que estimulou a articulação das sociedades empresárias, Governos e instituições de apoio em favor do desenvolvimento organizado dos Arranjos Produtivos Locais.

Os clusters propiciam efetivas vantagens empresariais, econômicas e sociais, dentre as quais podem ser destacadas: maior integração e sinergia entre as indústrias, compartilhamento de inovações e avanços tecnológicos, compartilhamento de infraestrutura e sistema de logística, relação de cooperação na prospecção de mercados (muito embora a concorrência também esteja presente dentro do APL), retenção da mão de obra na respectiva região (preservando a cultura e as tradições locais), estabelecimento de sistema educacional voltado à vocação regional, dentre várias outras.

Por sua vez, o desenvolvimento sustentável se perfaz da harmonização do crescimento econômico, da promoção do bem estar social e da preservação dos recursos naturais. Observa-se, portanto, que os clusters, concebidos e fomentados de forma planejada, organizada e bem articulada, com a participação das sociedades empresárias, do Poder Público e de instituições de apoio e suporte, são o melhor mecanismo para que a atividade econômica realize-se de forma plena e alinhada aos preceitos da sustentabilidade, o que responde ao temaproblema proposto na introdução.

Conclui-se, desse modo, que os clusters, que se caracterizam como sendo um modelo de atuação empresarial fundados na especialização e na regionalização do desenvolvimento, merecem atenção especial do Estado, a quem cabe adotar políticas de incentivo e planejamento, nos termos do artigo 174 da Constituição, visando a criação e o aprimoramento dos APLs e propiciando, com isso, o crescimento econômico e o bem estar social; pilares que, juntamente com a proteção e preservação ambiental, constituem-se no cerne do desenvolvimento sustentável.

\title{
CLUSTER - LOCAL PRODUCTIVE ARRANGEMENT - AS A TOOL FOR THE SUSTAINABLE DEVELOPMENT
}

\begin{abstract}
This paper aims to analyze the adequacy of the cluster model (Local Productive Arrangement - APL) as an effective tool in promoting sustainable and regionalized national development. Through descriptive bibliographic research, it sought to initially address the amplitude of the sustainability concept that, in addition to environmental considerations, is also based in economic development and social welfare. At this point, it was pointed out that the
\end{abstract}


Brazilian Constitution assigns to the Federation the function of encouraging and planning economic activity, and should therefore adopt policies that are aligned to the principle of sustainable and regionalized development. Therefore, we tried to show the main characteristics of clusters and the role of governance in their improvement, using APLs implemented in the State of Minas Gerais to illustrate successful cases of industrial clusters of this species. International experiences were also highlighted with clusters referring to those Italian, French, Portuguese and Spanish models. In the end, it was concluded that the Local Productive Arrangements, well organized and planned, are a business activity model which is consistent with the principles of sustainable and regionalized development, where the State should adopt public incentive policies and planning.

Keywords: Cluster, Local Productive Arrangement; Sustainable development; Incentive; Planning.

\section{REFERENCIAS}

AQUINO, André Luiz de; BRESCIANI, Luis Paulo. Arranjos produtivos locais: uma abordagem conceitual. Organizações em Contexto. São Paulo: UMESP, v. 1, n. 2, p. 153-167, jul./dez. 2005.

ARAÚJO, Jailton Macena; ARRUDA, Danilo Barbosa. Desenvolvimento sustentável: políticas públicas e educação ambiental no combate a desertificação do nordeste. Veredas do Direito. Belo Horizonte, v.7, n.13/14, p. 289-310, jan./dez. 2010.

AZEVEDO, Ana Cláudia; PARDINI, Daniel Jardim; SIMÃO, Gustavo Leonardo. Capital social e relacionamentos inter e intrarregionais em arranjos produtivos locais: estudo no APL calçadista de Nova Serrana/MG. Revista REGEPE. São Paulo, v.4, n.2, p. 96-132, 2015.

BANCO NACIONAL DE DESENVOLVIMENTO ECONÔMICO E SOCIAL - BNDES. Caracterização, análise e sugestões para adensamento das políticas de apoio a APLs implementadas: o caso do Estado de Minas Gerais.

Disponível

em: <http://www.bndes.gov.br/SiteBNDES/bndes/bndes_pt/Galerias/Arquivos/empresa/pesquisa/Caracterizac ao_MG.pdf>.Acesso em: 20 jul. 2015. 
BENKO, Georges. Distritos industriais e governança das economias locais: o caso da França. Interações. Campo Grande: UCDB, v. 6, n. 9, p. 9-24, set. 2004.

BITTENCOURT, Sidney. Licitações sustentáveis: o uso do poder de compra do Estado fomentando o desenvolvimento nacional sustentável. Belo Horizonte: Del Rey, 2014.

BRASIL. Constituição da República Federativa do Brasil. 2. ed. rev., ampl. e atual. São Paulo: RT, 2006.

CACCIAMALI, Maria Cristina. Aspectos da distribuição da renda no Brasil. In: PINHO, Diva Benevides; VASCONCELLOS, Marco Antonio Sandoval de (Org.). Manual de economia: equipe de professores da USP. São Paulo: Saraiva, 2001. cap. 19, p. 437-456.

ERBER, Fabio Stefano. Eficiência coletiva em arranjos produtivos locais industriais: comentando o conceito. Nova Economia. Belo Horizonte: FACE-UFMG, v. 18, n. 1, p. 11-31, jan./abr. 2008.

HOUAISS, Antônio; VILLAR, Mauro de Salles. Dicionário HOUAISS da língua portuguesa. Rio de Janeiro: Objetiva, 2009.

IACONO, Antonio; NAGANO, Marcelo Seido. Uma análise e reflexão sobre os principais instrumentos para o desenvolvimento sustentável dos arranjos produtivos locais no Brasil. Revista Gestão Industrial. Ponta Grossa: UTFPR, v. 3, n. 1, p. 37-51, 2007.

KELLER, Paulo Fernandes. Clusters, distritos industriais e cooperação interfirmas: uma revisão da literatura. Revista Economia \& Gestão. Belo Horizonte: PUCMINAS, v. 8, n. 16, p. 30-47, set. 2008.

LÓPEZ, Eugenio Climent. Sistemas productivos locales y distritos industriales: el caso de España. Boletin de la A.G.E.Valência (Espanha): A.G.E., n. 24, p. 91-106, 1997.

MACHADO, Paulo Affonso Leme. Direito ambiental brasileiro. 22. ed. rev., ampl. e atual. São Paulo: Malheiros, 2014. 
MELO, Ana Isabel. Distritos industriais marshallianos: o caso de Águeda. Revista Portuguesa de Estudos Regionais. Lisboa: APDR, n. 12, p. 29-51, 2006.

MURAD, Ronan de Brito; LIMA, Renato da Silva; NETO, Mário Sacomano. Gestão de relacionamento com fornecedores em arranjos produtivos locais: o caso do Vale da Eletrônica. Production. Itajubá, v. 25, n. 1, p. 1-12, jan./mar. 2015.

NARDES, João Augusto Ribeiro; ALTOUNIAN, Cláudio Sarian; VIEIRA, Luis Afonso Gomes. Governança pública: o desafio do Brasil. Belo Horizonte: Fórum, 2014.

PEREIRA, José Cláudio; LORENA, Rosa Stela Ribeiro de. Vantagens competitivas do cluster eletroeletrônicos de Santa Rita do Sapucaí - MG. Revista Científica da FAI. Santa Rita do Sapucaí, v.14, n.1, p. 60-71, 2014.

SANTOS, Heloisa Nazaré dos. Processos de produção e trabalho no Arranjo Produtivo Local calçadista de Nova Serrana. GEPROS. Bauru, n.2, p. 55-65, abr./jun. 2013.

SILVA, José Afonso da. Curso de direito constitucional positivo. 37. ed. rev. e atual. São Paulo: Malheiros, 2014.

SILVA NETO, Manoel Jorge e. Curso de direito constitucional. 6. ed. Rio de Janeiro: Lumen Juris, 2010.

SINDICATO DA INDÚSTRIA DO CALÇADO DE NOVA SERRANA - SINDINOVA. Plano de desenvolvimento do arranjo produtivo calçadista de Nova Serrana. Belo Horizonte: SINDINOVA, 2007. Disponível em: <http://www.desenvolvimento.gov.br/arquivos/dwnl_1248287878.pdf>. Acesso em: 20 jul. 2015.

SINDICATO DAS INDÚSTRIAS DE APARELHOS ELÉTRICOS, ELETRÔNICOS E SIMILARES DO VALE DA ELETRÔNICA - SINDVEL. Plano de desenvolvimento do arranjo produtivo eletroeletrônico de Santa Rita do Sapucaí. Belo Horizonte: SINDVEL, 2007. Disponível em: <http://www.desenvolvimento.gov.br/arquivos/dwnl_1248287838.pdf>. Acesso em: 20 jul. 2015.

THOMÉ, Romeu. Manual de direito ambiental. 4. ed. rev., ampl. e atual. Salvador: JusPodivm, 2014. 
Quaestio Iuris

Trabalho enviado em 18 de junho de 2018

Aceito em 17 de setembro de 2018 vol. $11, n^{\circ}$. 04, Rio de Janeiro, 2018. pp. 3352-3370 DOI: $10.12957 /$ rqi.2018.35102 